\title{
Editorial: Special issue introduction
}

\author{
Samir GARBAYA ${ }^{1}$ and Theodore LIM ${ }^{2}$ \\ ${ }^{I}$ END-ICAP Laboratory - INSERM, ENSAM, Arts et Métiers ParisTech, France, \\ samir.garbaya@ensam.eu \\ ${ }^{2}$ Heriot-Watt University, United Kingdom \\ T.Lim@hw.ac.uk
}

This special issue marks important milestones for the Serious Gaming Society (SGS) and its journal the International Journal of Serious Games. First, this special issue is dedicated to the gamification of industrial systems in the context of the widespread adoption of serious games in many fields such as education, medicine, military and industry. The potential for training by increasing motivation for engaged interaction and the adaptation of behavior has been proven. In addition, new emerging needs for gamification are identified in industry where important benefits could be generated by reducing the product cost and time-tomarket. Moreover, in the era of industry 4.0, which combines production methods with the state-of-the art information and communication technologies, serious games could have the potential to promote innovation and increase the resources and the production efficiency. However, despite the significant advances that have been made in game-based approaches to non-game contexts, its potential transition into industrial settings have not been realized. This is mainly due to challenging issues such as the lack of methodologies for modeling industrial scenarios in digital contents representing real industrial systems with high fidelity, operational processes must be fully digitalized to ease the integration of gamification concepts, the adaptation of work environment conditions so that the use of gaming on mobile devices can take place without the interruption of industrial activities.

This special issue focuses on the gamification of industrial systems. The diverse application domains reported in the published papers reflect the growing interest of the research community on gamification. The articles address important challenging issues through conducting pilot studies and developing gamified industrial applications.

The first highlight of this special edition is an article entitled "Gamification of a Procurement Process for Professional Training of Public Servants" [1] by Maksims Kornevs, Jannicke Baalsrud Hauge and Sebastiaan Meijer. This article explored how well gamification can address the complexity of the procurement process for training specialists in the road construction sector. They found that gamification of training helps to address the needs of the organization and participants in obtaining and applying new knowledge. They also showed the importance of aspects related to the complexity of the real system and how these aspects affect the results of gamification.

The second highlight is an article entitled "Capacity Building on Heat Balance in Electrolysis of Aluminium" [2] by Sobah Abbas Petersen, Manuel Oliveira, Kristin Hestetun, Gunn Iren Müller, Stein O. Wasbø, Victoria Koritzinsky and Anne Lise Waal. The authors described a digital simulation game designed and developed for the operators in aluminium plants to master the cognitive skills required for Heat Balance in the aluminium production cells. The evaluation they conducted showed that the game has the potential to support learning and appears to meet the expectations of the operators.

The third paper is entitled "Gamification in Management: a systematic review and research directions" [3], authored by Vanissa Wanick and Hong Bui. This paper presents a contemporary and inclusive review of initial applications of gamification to various management fields, such as finance, corporate governance, risk management, human resource management. They showed that gamified strategies vary according to each management field. The areas analyzed were Marketing and Tourism, Human Resource 
pag. 22

Management, Logistics and Supply Chain Management, Finance, Corporate Governance, Accountability and Sustainability and Healthcare Services. Their analysis allowed setting out a list of questions to direct future research in order to increase the impacts of this innovative and strategic research area within businesses and organizations.

The fourth paper entitled "Gamification concepts for leveraging knowledge sharing in Industry 4.0" [4] authored by Maria Tsourma, Stylianos Zikos, Georgios Albanis, Konstantinos C. Apostolakis, Evdoxia E. Lithoxoidou, Anastasios Drosou, Dimitrios Zarpalas, Petros Daras, and Dimitrios Tzovaras. This paper presented gamification concepts that are suitable for application in Industry 4.0 environments in the context of knowledge sharing. They presented a Social Media Platform that can be used internally in industrial environments and utilizes gamification mechanics. The objective of this implementation is to increase user's motivation and participation in knowledge sharing and training processes taking place on a factory's shop floor, enhance socialization and support corrective feedback and positive reinforcement.

The fifth paper entitled "User Acceptance Evaluation of a Gamified Knowledge Sharing Platform for Use in Industrial Environments" [6], authored by Stylianos Zikos, Maria Tsourma, Evdoxia E. Lithoxoidou, Anastasios Drosou, Dimosthenis Ioannidis and Dimitrios Tzovaras. The authors evaluated the user acceptance on a gamification-enabled collaboration and knowledge sharing platform. They showed that the ratings received from both workers and supervisors were very positive, especially for working experience and overall impact. They also highlighted important aspects that should be taken into account when developing similar platforms for industrial environments, and provided guidelines based on user feedback.

I would also like to take this opportunity to thank the members of the Editorial Board and the reviewers who have provided invaluable support through their voluntary efforts for reviewing the papers.

\section{References}

[1] M. Kornevs, J. Baalsrud Hauge and S. Meijer, Gamification of a Procurement Process for Professional Training of Public Servants, The International Journal of Serious Games, Vol. 6, No. 2, June 2019. http://dx.doi.org/10.17083/ijsg.v6i2.293

[2] S. Abbas Petersen, M. Oliveira, K. Hestetun, G. I. Müller, S. O. Wasbø, V. Koritzinsky and A. L. Waal, Capacity Building on Heat Balance in Electrolysis of Aluminium, The International Journal of Serious Games, Vol. 6, No. 2, June 2019. http://dx.doi.org/10.17083/ijsg.v6i2.285

[3] V. Wanick and H. Bui, Gamification in Management: a systematic review and research directions, The International Journal of Serious Games, Vol. 6, No. 2, June 2019. http://dx.doi.org/10.17083/ijsg.v6i2.282

[4] M. Tsourma, S. Zikos, G. Albanis, K. C. Apostolakis, E. E. Lithoxoidou, A. Drosou, D. Zarpalas, P. Daras, and D. Tzovaras, Gamification concepts for leveraging knowledge sharing in Industry 4.0, The International Journal of Serious Games, Vol. 6, No. 2, June 2019. http://dx.doi.org/10.17083/ijsg.v6i2.273

[5] S. Zikos, M. Tsourma, E. E. Lithoxoidou, A. Drosou, D. Ioannidis and D. Tzovaras, User Acceptance Evaluation of a Gamified Knowledge Sharing Platform for Use in Industrial Environments, The International Journal of Serious Games, Vol. 6, No. 2, June 2019. http://dx.doi.org/10.17083/ijsg.v6i2.275 